\title{
Uso da metodologia da problematização com o Arco de Maguerez no ensino sobre brinquedo terapêutico
}

\author{
Júnia Aparecida Laia da Mata Fujitai, Elenice Valentim \\ Carmonaii \& Antonieta Keiko Kakuda Shimoiii \\ Universidade Estadual de Campinas, Brasil \\ Elizane Henrique de Mecenaiv \\ Universidade Livre para a Eficiência Humana, Brasil
}

Resumo

Este estudo objetivou relatar a experiência do uso da metodologia da Problematização com apoio do Arco de Maguerez no ensino sobre brinquedo terapêutico na graduação de enfermagem, bem como os resultados alcançados. A experiência se deu com 52 alunos de uma instituição de ensino superior privada, localizada em Curitiba, Paraná, Brasil. Foram implementadas as cinco etapas do Arco de Maguerez: 1. Observação da realidade; 2. Pontos-chave; 3. Teorização; 4. Hipóteses de solução; 5. Aplicação à realidade - Prática. A experiência resultou na criação de dez brinquedos terapêuticos. Foram vivenciados diferentes aspectos inerentes ao processo de ensino-aprendizagem, constatando-se que uma educação de nível superior pautada no uso de metodologias ativas e não mais limitada à transmissão de conteúdos teóricos tem potencial para formar profissionais mais preparados para atender às atuais demandas em saúde.

Palavras-chave

Educação em enfermagem; Ensino; Aprendizagem baseada em problemas; Jogos e brinquedos 


\section{Introdução}

A formação tradicional em saúde, hegemônica nas Instituições de Ensino Superior (IES), decorre das recomendações de Abraham Flexner, que, em 1910, publicou o estudo Medical Education in the United States and Canada - A Report to the Carnegie Foundation for the Advancement of Teaching (Flexner, 1910), causando a mais importante reforma das escolas médicas de todos os tempos nos Estados Unidos da América, com intensas implicações na formação ao redor do mundo. O relatório de Flexner (1910) foi amplamente difundido e resultou em um modelo adotado pelas IES mundialmente. Desde então, a formação em saúde fundamenta-se em um ensino organizado em disciplinas, centrado no docente, com atividades práticas em cenário predominantemente hospitalar, marcado pela unidirecionalidade na relação professor-aluno e pela fragmentação do corpo e da saúde das pessoas (Gomes, Ribeiro, Monteiro, Leher, \& Louzada, 2010).

Tal formação é marcada historicamente pelo uso de metodologias tradicionais de ensino, sob influência do mecanicismo fundamentado no modelo cartesiano- newtoniano, que enfatiza os aspectos biológicos, fragmenta o saber e fortalece a dicotomia entre teoria e prática (Mitre et al., 2008; Silva \& Sá-Chaves, 2008). Nessa vertente, o processo de ensinoaprendizagem tem se limitado à reprodução de informação, no qual o professor exerce um papel de transmissor de conteúdo, enquanto ao aluno cabe reter e repetir o que recebe, em atitude passiva e reprodutora, tornandose mero expectador, sem empenho crítico e reflexivo (Mitre et al., 2008).

Desde a segunda metade do século $\mathrm{XX}$, tem crescido a preocupação com este modelo de ensino, convocando as IES a analisar seus métodos e suas concepções pedagógicas. Em 1980, já era percebido o despreparo dos profissionais para atuarem na saúde devido à discrepância entre formação e realidade da prática profissional. Nessa época, intensificou-se a mobilização de educadores na busca de transformação da educação tradicional para uma educação crítica, em prol das mudanças sociais (Almeida \& Ferraz, 2008). Foi neste cenário que se desenvolveram as teorias críticas, ressaltando-se a Pedagogia Libertadora ou Problematização, com destaque para o modelo educacional de Paulo Freire, que contribuiu significativamente para se repensar a educação na área da saúde (Luckesi, 1991). Tais teorias têm sido 
inseridas gradativamente em diferentes ambientes de ensino-aprendizagem, muitas vezes de forma lenta e difícil.

A educação superior em saúde vem passando por profundas mudanças para incorporar novas concepções que norteiam a formação do profissional e do docente (Prado, Velho, Espíndola, Sobrinho, \& Backes, 2012). Contudo, as metodologias de ensino tradicionais (ou conservadoras) continuam sendo amplamente aplicadas nas IES. Nessa modalidade de educação, denominada por Paulo Freire como "bancária", destaca-se a transferência de conhecimentos pelo professor ao estudante, a grande valorização da formação técnica e a dissociação entre o conhecimento teórico recebido passivamente pelo educando e o contexto social no qual está inserido (Freire, 2011c; Pereira, 2003).

Na perspectiva da pedagogia crítica, oposta à tradicional, o educador assume o papel de mediador, ao conduzir os alunos à observação da realidade e apreensão do conteúdo que extraem dela: um processo educativo que visa à transformação social, além da superação das desigualdades sociais (Pereira, 2003). Esse modelo pedagógico tem suscitado interesse como campo de pesquisa e investimento na prática educacional.

A neurociência e a psicologia cognitiva já comprovaram que fatos e conceitos são mais facilmente recordados e mobilizados quando ensinados, praticados e avaliados no contexto em que são utilizados - o que demanda uma reconfiguração das situações e dos cenários de ensino-aprendizagem disponibilizados para os discentes em sua formação (Cooke, Irby, Sullivan, \& Ludmerer, 2006). A aprendizagem se torna efetiva quando o conteúdo está presente no cotidiano dos educandos, sendo fundamental considerar o conhecimento que eles trazem da sua vivência e realidade.

Diante das profundas mudanças ocorridas nas diferentes áreas do conhecimento nas últimas décadas, têm surgido na área da saúde questionamentos sobre o perfil do profissional formado pelo modelo tradicional, centrado na transmissão de conhecimentos pelo docente ao estudante, no qual o professor é o único responsável pela condução do processo educativo e autoridade máxima na escolha das estratégias de ensino (Mitre et al., 2008). Muitas discussões apontam para a urgência da implementação de novas modalidades pedagógicas, convocando as IES a repensar seu papel (Sobral \& Campos, 2012). 
A mudança da educação na área da saúde envolve os desafios de romper com estruturas cristalizadas e modelos de ensino tradicional e formar profissionais de saúde com competências que lhes permitam resgatar a dimensão essencial do cuidado: a relação entre humanos (Cyrino \& TorallesPereira, 2004). Para isso, faz-se necessário a adoção de metodologias de ensino que levem em conta as experiências dos alunos e o contexto onde estão inseridos, proporcionando a problematização de suas respectivas práticas. As ações educativas devem essencialmente ser dirigidas à construção do conhecimento de forma ativa pelo discente. A metodologia ativa é uma das estratégias que coloca o aluno como protagonista do processo de ensino-aprendizagem, tornando-o corresponsável pela sua trajetória educacional, sendo o docente o coadjuvante, um facilitador das experiências relacionadas a este processo (Reibnitz \& Prado, 2006). A sua utilização implica em conhecer as formas de operacionalização e os princípios pedagógicos que a sustentam: os pilares da pedagogia crítica.

A Problematização é um dos modos fundamentais para a aplicação da metodologia ativa (Prado et al., 2012). Ela se opõe ao ensino tradicional, pois não opera na lógica da transferência de conhecimento, mas em movimentos que geram possibilidades para a sua produção ou construção (Freire, 2006). Tem por objetivo provocar o surgimento de outras formas de ensinar e aprender, nas quais professores e alunos sejam corresponsáveis por estes processos, estabelecendo entre si uma relação dialógica, em que a transferência de informações e memorização sejam substituídas pela construção ativa do conhecimento por meio de situações reais ou simuladas da prática profissional - o que pressupõe a indissociabilidade entre a teoria e o campo de práticas (Gomes et al., 2010).

O caminho a ser percorrido pelo discente, segundo a Problematização, parte da situação da realidade social observada que provoca questionamento, a partir do qual se desenha o quadro conceitual que permite uma análise teórica do problema. Coletam-se dados relevantes, formulam-se hipóteses norteadoras e chega-se a uma síntese ou solução, que envolve a transformação da realidade (Alves \& Berbel, 2012). O uso dessa metodologia está indicado sempre que os temas a serem trabalhados estejam relacionados com a vida em sociedade (Berbel, 1998). Considerando que esta característica é assídua nos cursos superiores de enfermagem, bem como na 
disciplina apresentada neste relato, optou-se por adotar a Problematização com o Arco de Maguerez (Bordenave \& Pereira, 2005) no ensino sobre brinquedo terapêutico (BT), conteúdo contemplado na sua ementa.

Diante da relevância do exposto, o presente estudo tem como objetivo relatar a experiência do uso da metodologia da Problematização com apoio do Arco de Maguerez no ensino sobre brinquedo terapêutico na graduação de enfermagem, bem como os resultados alcançados.

\section{A Problematização com o Arco de Maguerez e seu uso no ensino sobre brinquedo terapêutico}

O presente trabalho está alicerçado principalmente na obra de Paulo Freire (Freire, 2006, 2011a, 2011b, 2011c), a qual defende que a aprendizagem tem relação com o cenário, com o método de ensino e com a interação entre os indivíduos.

Nessa experiência foi utilizada a Problematização, que se fundamenta na pedagogia libertadora de Paulo Freire, nos princípios do materialismo histórico-dialético e no construtivismo de Piaget, tendo como referência o Arco de Charles Maguerez (Figura 1) (Alves, 2003; Bordenave \& Pereira, 2005). Essa metodologia consiste em cinco etapas: 1 . Observação da realidade; 2. Pontos-chave; 3. Teorização; 4. Hipóteses de solução; 5. Aplicação à realidade - Prática (Bordenave \& Pereira, 2005).

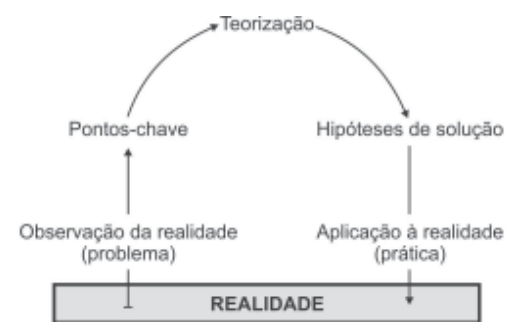

Figura 1 - Arco de Maguerez (Bordenave \& Pereira, 2005)

A primeira etapa, "Observação da realidade" e identificação do problema, envolve o início de um processo de apropriação de informações 
pelos sujeitos, que são conduzidos a observar a realidade em si, sob sua própria ótica, a identificar-Ihe características, a fim de poderem contribuir para a sua transformação (Berbel, 1995; Colombo \& Berbel, 2007).

Definido o problema, os indivíduos elegem os seus possíveis fatores e determinantes, realizando uma reflexão que culminará na definição dos "Pontos-chave", que podem ser expressos de diferentes maneiras: questões básicas, afirmações sobre características do problema, tópicos a serem investigados ou outras formas (Colombo \& Berbel, 2007).

Concluído o estabelecimento dos pontos-chave principia-se a "Teorização", na qual os indivíduos buscam construir respostas mais fundamentadas para a problemática. Uma teorização bem desenvolvida leva o aluno a compreender o problema, não somente em suas dimensões baseadas na experiência ou situação, mas também nos princípios teóricos que o explicam (Berbel, 1999; Bordenave \& Pereira, 2005; Colombo \& Berbel, 2007).

$\mathrm{Na}$ quarta etapa do Arco de Maguerez, "Hipóteses de solução", a criticidade, criatividade e originalidade devem ser fomentadas para se pensar nas alternativas de solução. $O$ estudante aprende com a realidade, ao mesmo tempo em que se prepara para transformá-la (Bordenave \& Pereira, 2005; Colombo \& Berbel, 2007).

O momento da "Aplicação à realidade" é aquele que possibilita implementar as soluções geradas no processo, a fim de transformar a realidade problematizada. Essa fase possibiliza o intervir, o exercitar e 0 manejar ocasiões relacionadas à solução do problema (Colombo \& Berbel, 2007; Reibnitz \& Prado, 2006).

A Problematização é uma perspectiva que acredita na educação como uma prática social/coletiva e não individual ou individualizante (Berbel, 1998). É uma metodologia de ensino que contribui para a constituição de profissionais críticos, com perfil para transformar o real a partir de sua prática e que oportuniza enxergar, estudar e modificar a realidade com maior criticidade, criatividade e resolutividade. Por isso, optou-se por aplicá-la no ensino sobre BT na graduação de enfermagem.

O BT constitui-se num brinquedo estruturado para a criança aliviar a ansiedade desencadeada por experiências atípicas para a sua idade, que 
costumam ser ameaçadoras e requererem mais do que recreação para tal alívio, devendo ser usado sempre que ela apresentar dificuldade em compreender e lidar com a experiência (Steele, 1981). Surgiu dos princípios da Ludoterapia e pode ser aplicado com qualquer criança, por enfermeiro devidamente familiarizado com a técnica (Rocha, Prado, \& Kusahara, 2005).

Existem três modalidades de BT: o dramático ou catártico, que permite a descarga emocional; o capacitador de funções fisiológicas, no qual a criança participa de atividades para melhorar o estado físico; e o instrucional, que prepara a criança, por meio da brincadeira, para os procedimentos a que será submetida, a fim de promover a compreensão sobre o tratamento e clarear conceitos equivocados (Vessey \& Mahon, 1990). As sessões de BT podem ser desenvolvidas em qualquer ambiente (em uma brinquedoteca, na enfermaria, no consultório, etc.).

Segundo a Resolução 295/2004 do Conselho Federal de Enfermagem (Cofen), cabe ao enfermeiro que atua na área pediátrica, como integrante da equipe multiprofissional de saúde, o uso da técnica do brinquedo terapêutico na assistência à criança e à família (Cofen, 2004). A aplicação do BT tem sido inserida gradualmente na prática assistencial às crianças, o que tem consolidado inúmeros benefícios no contexto do cuidado (Hall \& Reet, 2000; Maia, 2005). A enfermagem pode utilizar esta estratégia na atenção à saúde da criança, tanto na primária, quanto em situação de hospitalização.

No estudo de Leite (2004), que analisou quinze teses e dissertações de enfermeiros brasileiros sobre o uso do brinquedo no hospital, pautando sua análise nos efeitos que ele causava na criança, foi constatado que, ao ser aplicado em situações de pré e pós-operatório, o BT facilitou a comunicação e integração entre a criança e o profissional, ajudou a evidenciar os medos, proporcionou mudanças comportamentais significativas e catarse, além de servir de orientação. No contexto da hospitalização, as crianças mudaram de comportamento, interagindo mais, expressando suas satisfações, medos e ansiedades, além de evidenciar o aumento das brincadeiras no ambiente hospitalar (Leite, 2004).

O brincar é uma atividade lúdica essencial para o desenvolvimento infantil e integradora para a criança, e compreendê-lo é uma necessidade fundamental aos profissionais de saúde, sobretudo aos enfermeiros que atuam na assistência às crianças, devendo ser valorizada tanto quanto o 
exame físico, a administração de medicamentos, o curativo e outros cuidados (Ribeiro, Borba, \& Rezende, 2009). Ao planejar a sistematização da assistência de enfermagem à saúde da criança, os enfermeiros precisam prever, fornecer e facilitar a sua participação nos diferentes tipos de brincadeira, como estratégia de cuidado.

A importância de estudar o uso da Problematização com o Arco de Maguerez no ensino em enfermagem deve-se à existência de uma política nacional de saúde e formação de recursos humanos que estimula a revisão da orientação do ensino e da prática profissional da enfermagem (Almeida \& Ferraz, 2008; Mitre et al., 2008; Silva \& Sá-Chaves, 2008), com enfoque no atendimento às necessidades humanas e sociais. Defende-se que é significativo promover o conhecimento sobre métodos de ensinoaprendizagem que contribuam para a transformação do modelo atual da educação em enfermagem.

\section{Método}

Relatamos aqui a experiência realizada sobre o uso da metodologia da Problematização com o Arco de Maguerez no ensino sobre brinquedo terapêutico em uma disciplina curricular intitulada "Prática Clínica do Processo de Cuidar da Saúde da Mulher, da Criança e do Adolescente", oferecida no curso de graduação em enfermagem de uma instituição de ensino superior, localizada no município de Curitiba, Paraná, Brasil.

As atividades de ensino-aprendizagem foram desenvolvidas junto aos 52 alunos matriculados na disciplina, que estavam cursando $\circ 6^{\circ}$ e $\circ 7^{\circ}$ semestres letivos, entre os meses de agosto e novembro de 2013.

A proposta metodológica relatada buscou estabelecer relações entre as experiências vividas pelos estudantes nos cenários de prática e no cotidiano e o conteúdo teórico, procurando criar oportunidades para se refletir, discutir e construir conhecimento coletivamente.

\section{Relato da experiência e discussão}

\section{O cenário da experiência}

A disciplina abordada neste relato integra a matriz curricular da graduação em enfermagem como matéria obrigatória e oferece embasamento 
prático para a implementação dos cuidados de enfermagem na assistência à mulher e ao recém-nascido, à criança, ao adolescente e sua família, tendo como objetivos gerais: 1) executar o cuidado colaborativo nos diferentes cenários de atuação do enfermeiro, norteado pela interação entre a mulher, a família e os profissionais da saúde, adotando o processo de enfermagem como método de trabalho; e 2) desenvolver a formação técnico-científica do graduando para capacitá-lo a prestar assistência de enfermagem à mulher, à criança e ao adolescente, utilizando habilidades cognitivas, interpessoais e psicomotoras.

O curso de enfermagem da instituição de ensino superior onde se deu esta experiência não adota metodologias ativas em seu currículo. Contudo, oferece liberdade aos docentes para desenvolverem suas disciplinas conforme o modelo pedagógico que acreditam e seguem. A professora responsável pela disciplina sempre teve como princípio norteador de sua prática docente a pedagogia crítica e faz uso da estratégia da Problematização com o Arco de Maguerez desde o ano de 2008. O tema BT foi inserido pela professora no plano de ensino da disciplina no segundo semestre de 2013, integrando a Unidade V, sob o título "O Brinquedo na Assistência à Saúde da Criança", tendo como subunidades: a importância do brincar para a criança; brincar no contexto da assistência à saúde; características e funções do brinquedo; o brinquedo no preparo para procedimentos diagnósticos e terapêuticos; o brinquedo terapêutico no contexto da assistência à saúde. Durante o desenvolvimento da temática foram aplicadas as cinco etapas do Arco de Maguerez, em oito encontros (Alves, 2003; Bordenave \& Pereira, 2005). A iniciativa de ensinar sobre o BT, fundamentando-se na Problematização, repercutiu em desfechos muito positivos, como apresentado no quadro abaixo. 


\section{Quadro 1 - Síntese dos objetivos e desfechos de cada etapa da ação protagônica relatada}

\begin{tabular}{|c|c|c|}
\hline ETAPA & OBJETIVO & DESFECHOS \\
\hline $\begin{array}{l}\text { 1. Observação da } \\
\text { realidade }\end{array}$ & $\begin{array}{l}\text { Oportunizar aos alunos } \\
\text { uma aproximação do } \\
\text { tema "brinquedo } \\
\text { terapêutico", permitindo a } \\
\text { formulação do problema. }\end{array}$ & $\begin{array}{l}\text { - Contato dos alunos com a literatura científica e com cenários } \\
\text { relacionados ao tema do brinquedo terapêutico; } \\
\text { - } \quad \text { Protagonismo do aluno na busca de informações; } \\
\text { - } \quad \text { A oportunidade de pesquisar sobre o assunto mobilizou o } \\
\text { interesse dos discentes acerca da temática; } \\
\text { - A identificação pelo aluno das dificuldades e potencialidades } \\
\text { do uso do brinquedo terapêutico na área da Enfermagem; } \\
\text { - Discussão sobre o tema, com promoção da integração entre } \\
\text { os estudantes e construção coletiva do problema a ser } \\
\text { tratado; } \\
\text { - Participação ativa do aluno no processo de ensino- } \\
\text { aprendizagem. }\end{array}$ \\
\hline 2. Pontos-chave & $\begin{array}{l}\text { Promover a reflexão e } \\
\text { discussão coletiva sobre } \\
\text { as questões levantadas } \\
\text { pelos alunos na etapa da } \\
\text { observação da realidade, } \\
\text { estabelecendo os pontos- } \\
\text { chave. }\end{array}$ & $\begin{array}{l}\text { - Reflexão coletiva dos alunos acerca das questões } \\
\text { levantadas; } \\
\text { - } \quad \text { Maior criticidade do estudante para tratar do assunto; } \\
\text { - Elaboração dos pontos essenciais a serem estudados sobre } \\
\text { o tema, para compreendê-lo mais profundamente. }\end{array}$ \\
\hline 3. Teorização & $\begin{array}{l}\text { Promover a busca de } \\
\text { informações sobre o } \\
\text { brinquedo terapêutico, } \\
\text { dentro de cada ponto- } \\
\text { chave já definido. }\end{array}$ & $\begin{array}{l}\text { - Maior protagonismo do aluno na busca do conhecimento, } \\
\text { possibilitando confrontar os diferentes modos de ensinar e } \\
\text { aprender; } \\
\text { - Construção coletiva do conhecimento; } \\
\text { - Compartilhamento do poder entre os indivíduos envolvidos } \\
\text { no processo de ensino-aprendizagem. }\end{array}$ \\
\hline $\begin{array}{l}\text { 4. Hipóteses de } \\
\text { solução }\end{array}$ & $\begin{array}{l}\text { Elaborar soluções para } \\
\text { as questões tratadas, } \\
\text { subsidiadas pelas } \\
\text { informações } \\
\text { acessadas/levantadas } \\
\text { pelos alunos e oferecidas } \\
\text { pela professora. }\end{array}$ & $\begin{array}{l}\text { - Produção dos projetos propostos pelos alunos, marcados } \\
\text { pela inovação e criatividade; } \\
\text { - } \quad \text { Motivação acentuada dos estudantes em aprender e } \\
\text { desenvolver as atividades propostas; } \\
\text { - } \quad \text { Apresentação dos brinquedos terapêuticos criados pelos } \\
\text { alunos; } \\
\text { - Os acadêmicos adotaram um comportamento de } \\
\text { protagonismo no seu aprendizado acerca do tema proposto } \\
\text { pela docente; } \\
\text { - Proposta de aplicação à realidade, elaborada coletivamente. }\end{array}$ \\
\hline $\begin{array}{l}\text { 5. Aplicação à } \\
\text { realidade }\end{array}$ & $\begin{array}{l}\text { Aplicar à realidade o } \\
\text { produto da atividade } \\
\text { desenvolvida. }\end{array}$ & $\begin{array}{l}\text { - Realização do I Encontro sobre Brinquedo Terapêutico; } \\
\text { - Socialização do conhecimento produzido; } \\
\text { - Satisfação expressada pelos alunos em desenvolver as } \\
\text { atividades e difundir os resultados para a comunidade, } \\
\text { outros acadêmicos e profissionais. }\end{array}$ \\
\hline
\end{tabular}

A seguir são descritas as ações que oportunizaram alcançar os resultados apresentados.

\section{Aprendendo a aprender sobre o brinquedo terapêutico}

O brincar envolve inteiramente a criança, sendo um ato que faz parte dela. Independentemente de como vivencia sua infância, a criança brinca para experienciar, experimentar, vivenciar, elaborar e compreender o mundo em que vive. Pode ser visto como uma experiência de aprendizado e 
representar um vetor para que a criança elabore situações causadoras de sofrimento e estresse, distanciando-a, de certa forma, da realidade - o que parece nos mostrar o imbricamento entre o BT e os infantes.

Ao ministrar essa temática com o apoio da Problematização, a docente ofereceu liberdade aos alunos para elaborar conceitos, criar seus próprios brinquedos terapêuticos e intervir no cenário proposto. Desse modo, na etapa da "Observação da realidade", antecipando qualquer abordagem teórica sobre o assunto, foi proposto aos discentes: 1- Formar grupos de até 6 pessoas (formaram-se 10 grupos); 2- Pesquisar sobre o tema 'brinquedo terapêutico' em bases eletrônicas de dados (Medline, Lilacs, Teses USP, PubMed) e livros, estimulando a busca na biblioteca da instituição; 3- Buscar conhecer locais que utilizam o BT.

Os estudantes tiveram como questões gerais para a focalização do tema: 1 - O que é o brinquedo terapêutico?; 2- Como ele pode ser utilizado e em quais cenários?; 3- Que efeitos esta estratégia pode gerar?; 4- A enfermagem pode utilizá-lo? De que maneira? Nessa fase, a professora objetivou oportunizar aos acadêmicos uma aproximação com o assunto, permitindo a formulação do problema.

No encontro seguinte, iniciou-se a etapa de estabelecimento dos "Pontos-chave", na qual a turma se organizou em mesa-redonda e foram apresentados e discutidos os tópicos que emergiram na observação, a saber: a falta de conhecimento da enfermagem sobre o tema; o que é o BT e como o enfermeiro pode aplicá-lo na sua prática profissional; os efeitos do brinquedo no preparo da criança para procedimentos e exames; a necessidade de abordagem deste assunto na graduação, a fim de preparar o aluno para usar esta estratégia na prática; como a criança é percebida e tratada dentro dos serviços de saúde; campos para a aplicação do BT (atendimento ambulatorial, à criança vitimizada, no nível hospitalar); e o que as pesquisas revelam sobre o tema.

Tais itens foram discutidos no coletivo e foi proposto aos alunos: 1Revisitar a literatura científica que trata do assunto; 2- Criar brinquedos terapêuticos para crianças internadas na unidade pediátrica de um hospital selecionado pela docente, em comum acordo com os discentes (o perfil das crianças internadas na instituição foi apresentado antecipadamente aos acadêmicos); 3- Elaborar o manual de instrução de cada brinquedo criado; 4- 
Apresentar, após três semanas, os protótipos dos brinquedos. Esta proposta ancorou-se na dialogicidade Freireana, que acredita que o diálogo, aqui estabelecido entre a professora e seus alunos, pode ser um espaço aberto de compromisso e construção de conhecimento acerca de uma nova realidade (a própria forma de aprender dos alunos e o uso do brinquedo como instrumento de diálogo com pacientes pediátricos) (Freire, 2011c).

Nas semanas seguintes, a docente realizou orientações dos grupos, conforme a demanda dos estudantes, que foram estimulados a se reunirem para discussões e reflexões, a visitar locais que aplicam o brinquedo terapêutico e a conhecer profissionais que trabalham com esta estratégia. Essa foi a etapa de "Teorização", na qual os acadêmicos foram estimulados a construir respostas bem fundamentadas para os problemas estabelecidos na observação da realidade.

A orientação sob demanda, segundo Costa (2001) - a partir de seus estudos Freireanos na busca por uma pedagogia ativa em oposição à educação bancária -, chama-se de "Pedagogia da Presença": uma forma de ensinar em que o fazer-se presente na vida do educando é fundamental para a ação educativa.

A princípio, percebeu-se certo estranhamento e grande preocupação por parte dos discentes frente à proposta, visto que estavam "acostumados", talvez, com outras formas de aquisição de conhecimento que não o diálogo. Alguns referiram insegurança para desenvolver as atividades, pois ainda não haviam tido uma aula expositiva sobre o assunto, demonstrando dificuldades para protagonizarem seu processo de aprendizagem. Freire (2011c) pergunta, em uma de suas páginas de Pedagogia do Oprimido: "Como posso dialogar se temo a superação e se, só em pensar nela, sofro e definho?". Em situações como esta é que a Presença Pedagógica se torna fundamental para desencadear a transformação dos alunos - transformação esta que se espera que permeie sua atuação profissional.

Segundo a Pedagogia da Presença, deve-se buscar abertura (para ouvir os não saberes, as dúvidas, as expectativas), reciprocidade (interação pela qual as presenças se revelam mutuamente) e compromisso (tomado aqui como a busca conjunta, pelo apoio à solução do problema, ao não abandono do educando em seu processo de aprendizagem) (Costa, 2001). Acredita-se que o estranhamento inicial apresentado pelos estudantes, frente à proposta 
de condução do aprendizado, apresentada pela docente, esteja estreitamente relacionado ao modelo curricular no qual estão inseridos, norteado pela pedagogia tradicional e bancária (Freire, 2011c). Na busca pelo exercício de uma pedagogia crítica não deve haver a centralização do poder no professor, o que significa que o poder deve ser compartilhado entre os envolvidos tarefa esta nada simples, tanto para os professores, como para os alunos, que carregam em si, de modo arraigado, uma escola autoritária e basicamente frontal.

As metodologias ativas se fundamentam em um princípio teórico significativo: a autonomia (Freire, 2006). Esta tem oportunizado a articulação entre a universidade, o serviço e a comunidade, por possibilitar leitura e intervenção consistentes sobre a realidade, bem como valorizar os atores no processo da construção coletiva e seus diferentes saberes, além de promover a liberdade no processo de pensar e no trabalho em equipe (Feuerwerker \& Sena, 2002; Feuerwerker, 2004).

Nessa experiência, em busca de protagonismo e autodidatismo, os alunos foram estimulados a desenvolver uma ação protagônica, com enfoque colaborativo (Costa, 2000, 2001). O processo de ensino-aprendizagem sobre o brinquedo terapêutico foi permeado pela corresponsabilização dos atores na tomada de decisões, no planejamento, na avaliação e na apropriação dos resultados. Ao dividir a responsabilidade pelo trabalho com seus estudantes, a professora oportunizou que estes se envolvessem com problemas reais e, possivelmente, cotidianos ao enfermeiro que atua com a criança e a infância. Ao fazer este movimento os acadêmicos são convidados a assumir uma postura de ser parte da solução do problema - que, no caso, se refere a contribuir com o entendimento do processo terapêutico das crianças mediado pelo BT. Tal ação impele os estudantes a se aproximar mais dos processos de humanização na saúde da criança, tão importantes nos tempos atuais.

Após três semanas do início da atividade, foi organizada outra mesaredonda, na qual os alunos tiveram a oportunidade de apresentar e discutir os protótipos dos brinquedos em sala de aula, iniciando a etapa "Hipóteses de solução". Nesse encontro, os discentes trocaram informações e sugeriram melhorias nos projetos uns dos outros, a fim de atender melhor o perfil das crianças internadas na instituição-cenário da intervenção. Alguns grupos modificaram completamente seus projetos após essa etapa. No encerramento 
da mesa-redonda a professora sugeriu: 1- A finalização dos brinquedos em três semanas e a apresentação final dos mesmos para a turma, em modalidade escolhida livremente pelo grupo (dramatização, oral com utilização ou não de recursos audiovisuais, vídeo, etc.); 2- Após a apresentação dos trabalhos, a turma poderia escolher os melhores e estes receberiam um certificado de reconhecimento; 3- Os grupos premiados poderiam doar os brinquedos elaborados ao hospital selecionado e objeto de observação, assim como compartilhar com os profissionais de saúde do local a forma de uso dos brinquedos. Os alunos mostraram-se eufóricos nesta etapa, transparecendo grande motivação para o desenvolvimento e a finalização da ação, sentindo-se comprometidos com uma causa (da qual, muitas vezes, as IES teimam em manter-se apartadas). Assim, passaram a comportar-se como protagonistas de sua formação (Costa, n. d.).

Antecipando as apresentações dos trabalhos em sala de aula, a professora fez uma explanação sobre o tema, esclarecendo as dúvidas dos discentes. Ao longo das apresentações, os acadêmicos demonstraram criatividade e originalidade, buscaram sensibilizar seus colegas quanto ao uso do brinquedo elaborado, bem como ensiná-los como aplicá-lo. Os trabalhos foram apresentados por meio das seguintes estratégias: seminário, dramatização e aula expositiva dialogada com apoio de recurso audiovisual. Os discentes discutiram os seguintes aspectos: a importância do uso do brinquedo no cuidado de enfermagem na saúde da criança; os pontos positivos da participação do enfermeiro na aplicação do brinquedo terapêutico; a importância da equipe de enfermagem compreender o brincar como uma necessidade humana básica da criança; a inserção do brincar no planejamento da sistematização da assistência de enfermagem; a segurança e a higienização do brinquedo; e a necessidade de inserção deste tema na graduação, bem como de preparar os alunos e profissionais para utilizar tal estratégia.

Todos os grupos apresentaram evidências científicas sobre o uso do brinquedo terapêutico e conceitos consistentes. Além disso, demonstraram inovação ao mesmo tempo em que seguiram as orientações oferecidas pela docente ao longo do processo, pois todos os brinquedos foram elaborados conforme as fases do desenvolvimento infantil, sendo aplicados de acordo com as habilidades da criança e a faixa etária; e foram feitos manualmente, utilizando também materiais recicláveis. 
Após as apresentações, realizou-se mais uma discussão, na qual surgiu a ideia coletiva de criar uma maneira para socializar o assunto dentro da faculdade e para a comunidade. Assim, foi proposta a realização de um evento, organizado pela professora e pelos alunos, no qual os brinquedos seriam apresentados à comunidade e aos discentes de outros cursos, contemplando uma palestra sobre o tema, contribuindo assim com o processo de apropriação dos resultados da ação pelo estudante.

Foram realizadas mais três reuniões para o planejamento do evento. Na primeira, os alunos elegeram uma comissão organizadora, constituída por: três discentes, de diferentes grupos, responsáveis pela elaboração da palestra sobre o BT, bem como pela compilação de toda a produção da turma sobre o assunto a apresentar; e outros três acadêmicos, responsáveis pela divulgação do evento na faculdade e na comunidade. Foi criada pela comissão uma página sobre o evento em uma rede social, na qual os alunos o divulgaram e convidaram pessoas. Além disso, elaboraram um convite virtual que foi encaminhado por e-mail para os alunos dos diferentes cursos da instituição-cenário do relato e outras externas, para serviços de saúde e para a população em geral.

Por fim, foi implementada a quinta etapa, a "Aplicação à realidade", na qual os alunos realizaram, sob orientação da professora, o I Encontro sobre Brinquedo Terapêutico. Participaram do evento alunos de outros cursos de graduação da instituição, docentes e pessoas da comunidade, principalmente crianças. Os acadêmicos montaram stands para apresentar o material elaborado e, após o evento, os brinquedos foram entregues à coordenação do curso para doação ao hospital. Após a escolha dos três melhores trabalhos, realizada pela turma, a premiação foi feita em forma de certificado de reconhecimento. Os grupos contemplados ficaram responsáveis por participar da doação dos brinquedos e orientação dos profissionais que os receberiam.

A estratégia utilizada pela docente evidenciou que o envolvimento do estudante com os problemas reais do seu cotidiano de trabalho/prática pode ser considerado um importante contributo para inovar as metodologias na formação dos enfermeiros. 


\section{Brinquedos terapêuticos resultantes da ação protagônica}

O uso da Problematização com o Arco de Maguerez na ação desenvolvida possibilitou aos alunos exercer sua aprendizagem de forma livre, autônoma, criativa e inovadora. As etapas do ensino sobre o BT foram realizadas de maneira colaborativa e a professora assumiu o papel de facilitadora do processo de ensino-aprendizagem. A seguir estão descritos os dez brinquedos resultantes da ação protagônica.

Brinquedo "Brincar e Aprender" (Figura 2): trata-se de uma caixa intitulada "Brincar e Aprender", que contém em seu interior vogais plastificadas, um conjunto de bolinhas coloridas e imagens de objetos comumente utilizados na assistência de enfermagem, a saber: agulha, estetoscópio, abaixador de língua, seringa, óculos de proteção, entre outros. É um brinquedo instrucional, que tem como principal objetivo familiarizar a criança com os materiais utilizados pela enfermagem, aproximando-a dos profissionais. Visa preparar a criança para os procedimentos de ausculta, aplicação de injeção e verificação de sinais vitais. O tempo proposto para sua aplicação é de 15 a 20 minutos, para crianças de 3 a 5 anos. Os tipos de atividades envolvidas na sua implementação são: motora, recreativa e estimuladora.

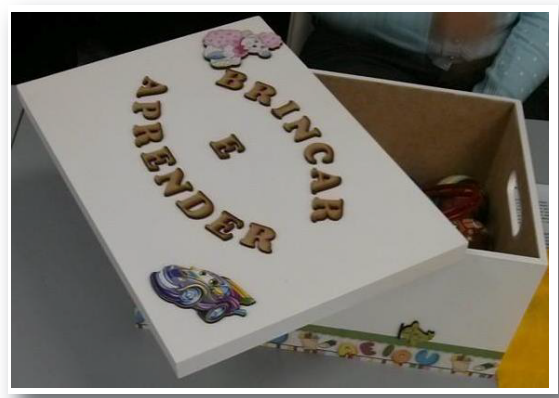

Figura 2 - Brinquedo "Brincar e Aprender"

Brinquedo "Boneca para Cateterização Nasogástrica" (Figura 3): constitui-se de uma boneca com orifícios nas narinas que possibilitam a passagem de uma sonda nasogástrica, uma sonda gástrica e outros materiais utilizados no procedimento. Ao brincar com a criança, o enfermeiro mostra o 
brinquedo, realiza o procedimento na boneca e, posteriormente, oferece à criança para repetir a ação. Após a brincadeira, propõe à criança que o deixe realizar o procedimento nela. É um brinquedo instrucional, que tem por objetivos: proporcionar uma relação de confiança entre a criança e o enfermeiro; diminuir as tensões do infante, relacionadas ao procedimento ao qual será submetido; e orientar a criança e seus familiares sobre o procedimento de cateterização nasogástrica. Sugere-se seu uso para crianças de 5 a 10 anos de idade, com o tempo de aplicação de 15 a 45 minutos.

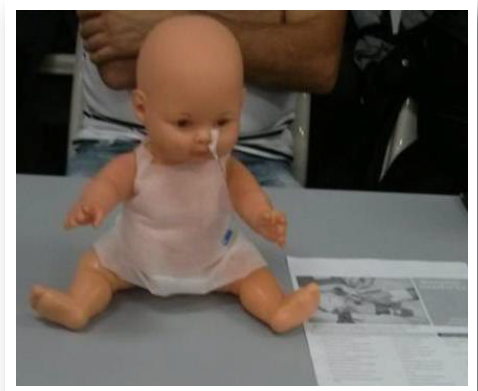

Figura 3 - Brinquedo "Boneca para Cateterização Nasogástrica"

Brinquedo "Super Nurse e Pacientezinho" (Figura 4): são dois fantoches, sendo que um representa uma enfermeira (Super Nurse) e o outro, a criança (Pacientezinho). Podem ser utilizados no preparo para qualquer procedimento de enfermagem, sendo que a criança pode trocar de papel com o profissional na aplicação do BT, facilitando uma comunicação terapêutica eficiente. A Super Nurse deve estimular a criança a manusear 0 Pacientezinho, orientando-a sobre o procedimento a ser realizado. Trata-se de um brinquedo dramático/catártico e instrucional, que objetiva permitir a descarga emocional da criança e prepará-la para os procedimentos aos quais será submetida. A faixa etária para o seu uso é de 4 a 6 anos de idade, numa sessão de 15 a 20 minutos. Os tipos de atividades envolvidas são: simbólica e recreativa.

A dramatização de papéis ou de conflitos, levando a uma redução da ansiedade pela ação da catarse, é tão importante que constitui a base do BT 
(Ribeiro et al., 2002). Possibilita a compreensão de significados das situações que muitas vezes a criança é incapaz de verbalizar (Santos, Borba, \& Sabatés, 2000).

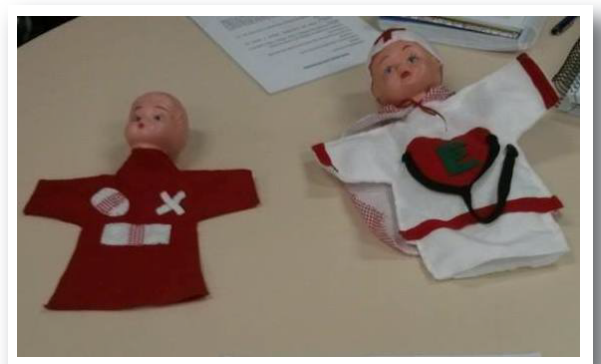

Figura 4 - Brinquedo "Super Nurse e Pacientezinho"

Brinquedo "Trilha da Saúde" (Figura 5): trata-se de um jogo constituído por um tapete de lona, que possui 25 casas, coloridas e com ilustrações. Cada casa tem uma atividade a ser realizada com a criança, sempre contendo informações sobre cuidados e procedimentos de enfermagem. Também possui um dado gigante em espuma vinílica acetinada (EVA), colorido, constituído por seis lados numerados sequencialmente. Neste brinquedo propõe-se à criança jogar o dado e avançar nas casas, conforme os números sorteados. Durante o percurso, o infante será convidado a realizar a dramatização de papéis. A modalidade deste brinquedo é dramática/catártica e instrucional, tendo como objetivos: preparar crianças hospitalizadas para procedimentos de enfermagem; aproximar a criança da enfermagem; e aliviar tensões. Pode ser aplicado a crianças a partir de 6 anos de idade e a adolescentes até 12 anos, sendo necessários 15 a 45 minutos. Os tipos de atividades envolvidas são: socializadora e dramática. 


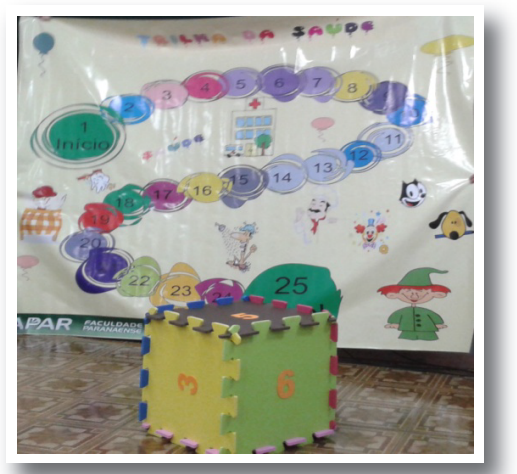

Figura 5 - Brinquedo "Trilha da Saúde"

Brinquedo "Contos de Luz" (Figura 6): é uma luminária giratória com recortes em forma de estrelas e animais que vem acompanhada de uma estória sobre uma criança internada que apresenta muitas dúvidas. Para sua aplicação, o ambiente deve permanecer com penumbra e a música pode ser utilizada. Trata-se de um brinquedo catártico, que objetiva: auxiliar a criança a enfrentar a internação de maneira menos traumática; amenizar o sofrimento da criança e acalmá-la; e liberar tensões antes de procedimentos. Pode ser aplicado a crianças de 2 a 7 anos de idade, por um tempo de 20 a 30 minutos.

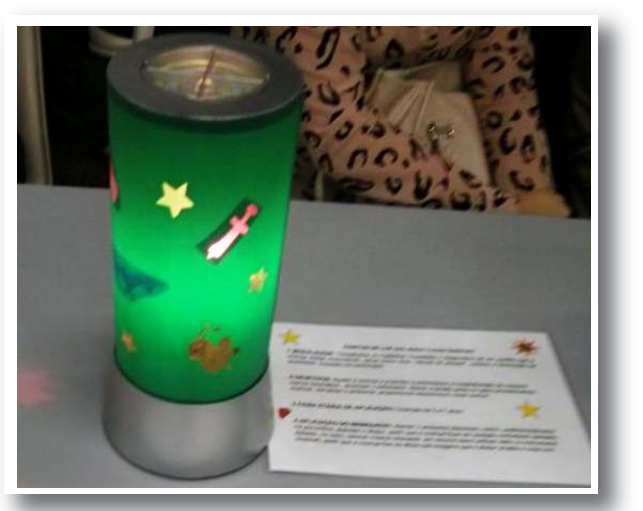

Figura 6 - Brinquedo "Contos de Luz" 
Brinquedo "Boneca para Quimioterapia" (Figura 7): trata-se de uma boneca com um cateter totalmente implantado, que tem por objetivo preparar crianças pré-escolares para submissão à quimioterapia, visando diminuir o estresse e o desgaste físico e emocional da criança e da família. É um brinquedo instrucional, que deve ser aplicado antes da quimioterapia. $\mathrm{Na}$ brincadeira, a criança é convidada a manusear materiais e a dramatizar 0 procedimento, podendo assimilar melhor a situação que será vivenciada. Pode ser aplicado de 15 a 20 minutos.

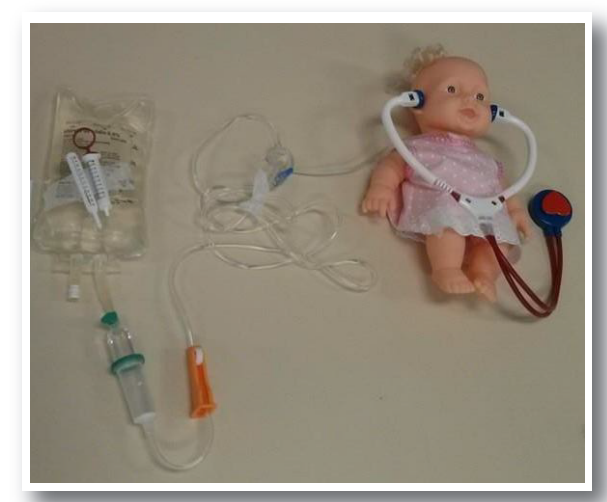

Figura 7 - Brinquedo "Boneca para Quimioterapia"

Brinquedo "Boneca Estrelinha" (Figura 8): é um brinquedo instrucional, que tem como objetivo preparar a criança para a passagem de cateter central. É aplicável à faixa etária de 3 a 6 anos. A criança deve ser convidada a brincar com a "Boneca Estrelinha", manuseando o cateter central. O profissional assume o papel de mediador na brincadeira, estimulando a criança a conhecer o dispositivo, bem como os cuidados com o mesmo. O tempo de aplicação deste BT é de 30 minutos. 


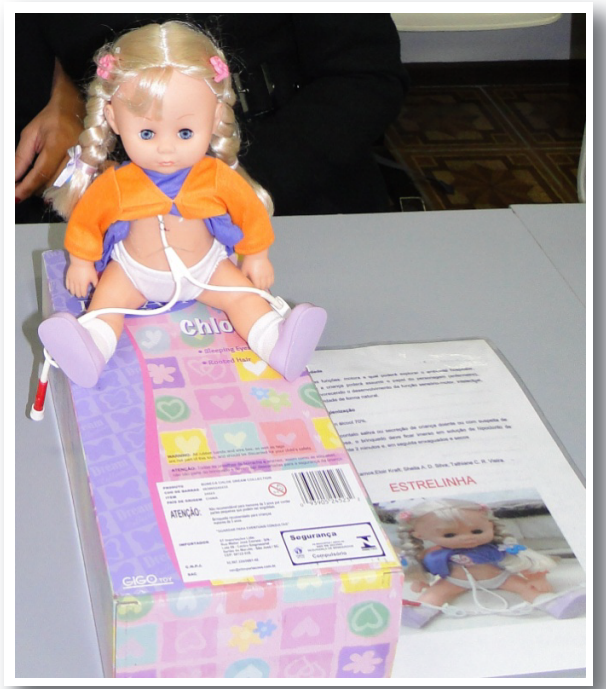

Figura 8 - Brinquedo "Boneca Estrelinha"

Brinquedo "Câmera Mágica" (Figura 9): trata-se de uma câmera fotográfica feita com material reciclável, que tem por objetivo preparar a criança para o procedimento de raios-x. A câmera possui uma lanterna com diodo emissor de luz (ou luz de LED - Light Emitting Diode), acoplado em sua face anterior, que acende ao ser apertado um botão, localizado na sua parte superior. No lado posterior, possui recortes de raios-x pediátricos (mãos, tórax e crânio) unidos a um pedaço de madeira e a uma tampinha de garrafa de politereftalato de etileno (PET), num circuito giratório. Ao girar a tampa, a criança tem acesso às imagens de raios-x. Para a sua aplicação, o profissional simula a realização de fotos da criança, exatamente das regiões similares às que o brinquedo apresenta nas lâminas de raios-x. Além disso, deve estimular a criança a manusear o brinquedo e a tirar fotos do profissional ou do familiar. Posteriormente à brincadeira, mostra as imagens fictícias à criança, promovendo um momento de recreação e catarse. Em seguida, a convida para continuar a brincar com uma máquina fotográfica muito maior, a de raios-x, realizando o exame necessário. O brinquedo pode ser aplicado para crianças de até 10 anos. O tempo de aplicação é variável (média de 40 minutos). 


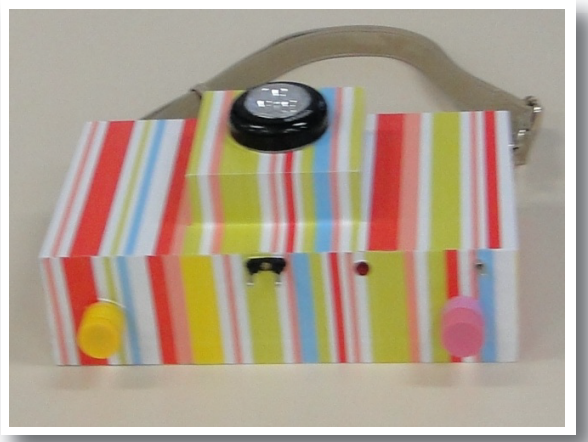

Figura 9 - Brinquedo "Câmera Mágica"

Brinquedo "Caixa Mágica" (Figura 10): trata-se de uma caixa personalizada, que possui uma série de materiais e instrumentos de trabalho da enfermagem (estetoscópio, termômetro, seringas, etc.) e fantoches (a Enfermeira e o "Doutô"). Em sua tampa é contada uma estória que envolve uma criança, uma enfermeira e um médico. Na brincadeira, a criança deve ser estimulada a ler a estória, conforme seu nível de alfabetização, ou o profissional realiza a leitura. Posteriormente, a caixa é aberta para que a criança possa conhecer e manusear os materiais, contando sua própria história com a utilização dos fantoches que estão na caixa. É aplicável dos 3 aos 7 anos de idade. A duração varia conforme a ação do profissional e a necessidade do infante (média de 30 minutos).

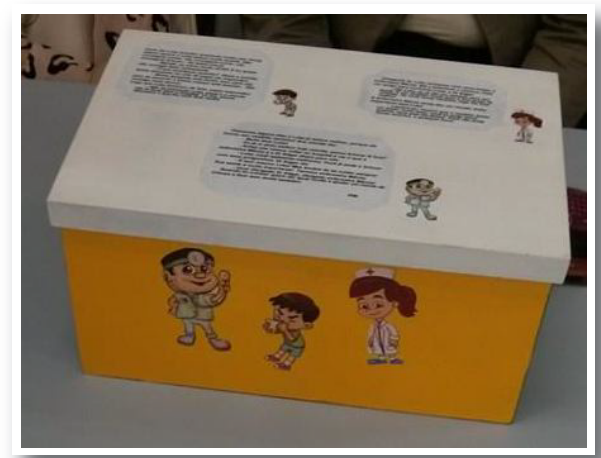

Figura 10 - Brinquedo "Caixa Mágica" 
Brinquedo "Boneca para Cateterização Vesical de Demora" (Figura 11): é um brinquedo instrucional, que tem por objetivo instruir a criança quanto ao procedimento de cateterização vesical de demora. $\mathrm{Na}$ brincadeira, o profissional explica sobre a cateterização e estimula a criança a manusear os materiais e realizar o procedimento na boneca. Quando o cateter vesical é inserido na boneca, flui um líquido para dentro da bolsa coletora (representando a urina). Recomenda-se que a sessão dure de 20 a 40 minutos, sendo aplicada para crianças de 5 a 10 anos.

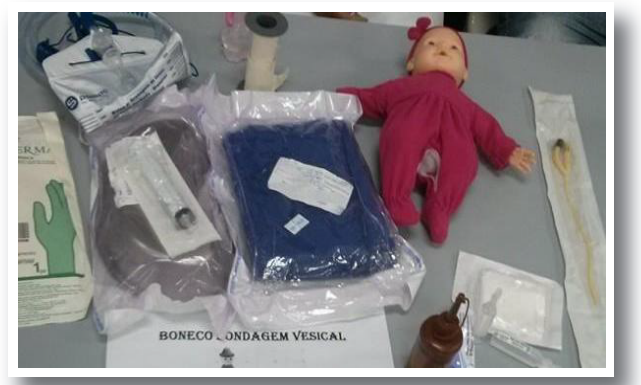

Figura 11- Brinquedo "Boneca para Cateterização Vesical de Demora"

O BT tem sido aplicado por enfermeiros na preparação de crianças para procedimentos e para amenizar a ansiedade perante a hospitalização (Rocha et al., 2005; Santos et al., 2000). Revela-se como uma estratégia de cuidado que pode contribuir para uma melhor compreensão das necessidades da criança, servir como um meio de comunicação entre o profissional e o infante, favorecendo o vínculo entre enfermeiro-criança, promovendo o desenvolvimento físico, psicológico, social e moral, além da satisfação e diversão (Rocha et al., 2005) - fatores que foram considerados na criação e construção dos brinquedos descritos.

Diante dos resultados apresentados, verifica-se que os alunos superaram os objetivos propostos no início da ação. A metodologia da Problematização com o Arco de Maguerez potencializou o processo de ensino-aprendizagem, despertou a criatividade e o potencial inovador dos discentes, favorecendo a criação de brinquedos terapêuticos originais e com grande aplicabilidade ao hospital selecionado. 
A maioria dos discentes expressou grande satisfação ao concluir a atividade e destacou que a maneira como foi ensinada sobre o tema possibilitou maior liberdade, autonomia e assimilação no processo de ensinoaprendizagem. Alguns alunos manifestaram o interesse em patentear seus brinquedos e foram incentivados a buscar informações sobre como poderiam proceder para a aquisição de uma patente. Os brinquedos premiados foram: $1^{\circ}$ lugar - "Câmera Mágica"; $2^{\circ}$ lugar - "Caixa Mágica"; $3^{\circ}$ lugar -"Trilha da Saúde". A professora organizou um momento solene, no final da disciplina, para que a turma pudesse prestigiar os trabalhos escolhidos.

A experiência relatada evidencia os aspectos positivos da pedagogia libertadora, que atribui ao aluno o protagonismo no processo de ensinoaprendizagem, tornando-o corresponsável na constituição do seu conhecimento. Confirma, também, a importância de se transformarem as práticas hegemônicas de ensino no campo da saúde, que hoje legitimam os paradigmas tradicionais, centradas na autonomia do professor e na passividade do aluno. Tais práticas só serão transformadas a partir do momento em que forem inseridas novas formas de ensinar que, por sua vez, provoquem a constituição de novos saberes e fazeres. É preciso admitir que a educação de nível superior pautada no uso de metodologias ativas e não mais limitada à transmissão de conteúdos teóricos tem potencial para formar profissionais mais preparados para atender às atuais demandas em saúde.

\section{Considerações finais}

$\mathrm{Na}$ experiência relatada verificou-se o quanto os alunos foram criativos, exerceram a criticidade e protagonizaram seu processo de ensinoaprendizagem, elaborando brinquedos terapêuticos de ótima qualidade que podem ser replicados e usados em diferentes ambientes.

Diante das diversas transformações ocorridas no campo da saúde, que têm demandado novas posturas em face aos obstáculos e desafios impostos, surge a necessidade de formar indivíduos críticos, reflexivos, autônomos, criativos e inovadores. A experiência descrita reforçou o valor da utilização de métodos pedagógicos mais flexíveis, que promovam a democratização das relações entre professores e alunos e a construção conjunta dos conhecimentos, a partir das experiências e vivências dos envolvidos. 
O uso da Problematização com o Arco de Maguerez no ensino sobre o BT na graduação em enfermagem mostrou-se significativo, pois permitiu a interligação entre teoria e prática, o exercício da construção coletiva do conhecimento e o estímulo à criatividade e ao pensamento crítico nos alunos, corroborando com os autores mencionados previamente. Esta experiência possibilitou também vivenciar as dificuldades inerentes ao processo de ensino-aprendizagem. $\mathrm{O}$ "passeio" pelas etapas de uma ação protagônica, como apresentado neste artigo, foi um relevante exercício para os alunos e para a instituição que ancorou a pesquisa, isto porque todos foram convidados a transitar da dependência do docente à autonomia para a execução das tarefas propostas.

Mesmo não sendo objeto deste trabalho, esta experiência revelou o resultado escolar de anos de educação bancária, centrada no professor, a que foram submetidos os estudantes do estudo. Por isso, inicialmente apresentaram resistência e dificuldades para a implementação da proposta. Este relato suscita, ainda, que o uso e a prática de uma educação mais dialógica, amparada em bases da presença, pode colaborar para a formação de profissionais mais humanos, mais solidários e próximos das realidades e pessoas com as quais possivelmente atuarão. Felizmente, há inúmeras possibilidades de aplicação da Problematização na graduação em enfermagem. Assim, outros trabalhos científicos sobre a temática podem ser desenvolvidos e compartilhados.

\section{Nota}

Agradecemos aos alunos que participaram da experiência, tornando-a possível e exitosa, desenvolvendo as atividades propostas com criatividade e espírito inovador.

\section{Referências}

Almeida, L. P. G., \& Ferraz, C. A. (2008). Políticas de formação de recursos humanos em saúde e enfermagem. Revista Brasileira de Enfermagem, 61(1), 31-35.

Alves, R. (2003). Conversas sobre educação. Campinas: Verus. 
254 Júnia Aparecida Laia da Mata Fujita et al.

Alves, E., \& Berbel, N. (2012). A resolução de problemas no contexto de um currículo integrado de enfermagem. Ciência, Cuidado e Saúde, 11(supl.), 191-198.

Berbel, N. (1995). Metodologia da problematização: Uma alternativa metodológica para o ensino superior. Semina: Ciências Sociais e Humanas, 16(2), 9-19.

Berbel, N. (1998). A problematização e a aprendizagem baseada em problemas: Diferentes termos ou diferentes caminhos? Interface - Comunicação, Saúde, Educação, 2(2), 139-154.

Berbel, N. (1999). Metodologia da problematização: Fundamentos e aplicações. Londrina: Ed INP/UEL.

Bordenave, J., \& Pereira, A. (2005). A estratégia de ensino-aprendizagem (26a ed.). Petrópolis: Vozes.

Conselho Federal de Enfermagem [Cofen] (2004). Resolução 295, de 24 de outubro de 2004. Dispõe sobre a utilização da técnica do brinquedo/brinquedo terapêutico na assistência à criança hospitalizada.

Colombo, A., \& Berbel, N. (2007). A metodologia da problematização com o Arco de Maguerez e sua relação com os saberes de professores. Semina: Ciências Sociais e Humanas, 28(2), 121-146.

Cooke, M., Irby, D., Sullivan, W., \& Ludmerer, K. (2006). American medical education 100 years after the Flexner Report. The New England Journal of Medicine, 355(13), 1339-1344.

Costa, A. (2000). Protagonismo juvenil: Adolescência, educação e participação democrática. Salvador: Fundação Odebrecht.

Costa, A. (2001). Pedagogia da presença: Da solidão ao encontro (2 ${ }^{\mathrm{a}}$ ed.). Belo Horizonte: Modus Faciendi.

Costa, A. (n.d.). O protagonismo juvenil passo a passo: Um guia para o educador. Belo Horizonte: Modus Faciendi.

Cyrino, E., \& Toralles-Pereira, M. (2004). Trabalhando com estratégias de ensinoaprendizado por descoberta na área da saúde: A problematização e a aprendizagem baseada em problemas. Cadernos de de Saúde Pública, 20(3), 780-788.

Feuerwerker, L., \& Sena, R. (2002). A contribuição ao movimento de mudança na formação profissional em saúde: Uma avaliação das experiências UNI. Interface - Comunicação, Saúde, Educação, 6(10), 37-50.

Feuerwerker, L. (2004). Gestão dos processos de mudança na graduação em medicina. In J. Marins, S. Rego, J. Lampert, \& J. Araújo (Org.), Educação médica em transformação: Instrumentos para a construção de novas realidades (pp. 1739). São Paulo: Hucitec.

Flexner, A. (1910). Medical education in the United States and Canada: A report to the Carnegie Foundation for the Advancement of Teaching - Bulletin Number 4. New York: Carnegie Foundation for the Advancement of Teaching.

Freire, P. (2006). Pedagogia da autonomia: Saberes necessários à prática educativa (33 ed.). São Paulo: Paz e Terra. 
Freire, P. (2011a). Educação como prática da liberdade (14ª ed.). Rio de Janeiro: Paz e Terra.

Freire, P. (2011b). Pedagogia da esperança (16 ed.). Rio de Janeiro: Paz e Terra.

Freire, P. (2011c). Pedagogia do oprimido (50 ed.). Rio de Janeiro: Paz e Terra.

Gomes, M., Ribeiro, V., Monteiro, D., Leher, E., \& Louzada, R. (2010). O uso de metodologias ativas no ensino de graduação nas ciências sociais e da saúde Avaliação dos estudantes. Ciência \& Educação, 16(1), 181-198.

Hall, C., \& Reet, M. (2000). Enhancing the state of play in children's nursing. Journal of Child Health Care, 4(2), 49-54.

Leite, T. (2004). Produção acadêmica de enfermeiros brasileiros sobre a utilização do brinquedo no hospital (Dissertação de mestrado). Universidade Estadual de Campinas, Campinas, São Paulo.

Luckesi, C. (1991). Filosofia da educação (3a ed.). São Paulo: Cortez.

Maia, E. (2005). Valorizando o brinquedo terapêutico como um instrumento de intervenção de enfermagem: O caminhar da enfermeira para essa sensibilização (Dissertação de mestrado). Universidade Federal de São Paulo, São Paulo.

Mitre, S., Siqueira-Batista, R., Girardi-de-Mendonça, J., Morais-Pinto, N., Meirelles, C., Pinto-Porto, C., Moreira, T., \& Hoffman, L. (2008). Metodologias ativas de ensino-aprendizagem na formação profissional em saúde: Debates atuais. Ciência \& Saúde Coletiva, 13(Supl. 2), 2133-2144.

Pereira, A. (2003). As tendências pedagógicas e a prática educativa nas ciências da saúde. Cadernos de Saúde Pública, 19(5), 1527-1534.

Prado, M., Velho, M., Espíndola, D., Sobrinho, S., \& Backes, V. (2012). Arco de Charles Maguerez: Refletindo estratégias de metodologia ativa na formação de profissionais de saúde. Escola Anna Nery - Revista de Enfermagem, 16(1), 172-177.

Reibnitz, K., \& Prado, M. (2006). Inovação e educação em enfermagem. Florianópolis: Cidade Futura.

Ribeiro, C., Maia, E. Sabatés, A., Borba, R., Rezende, M., \& Almeida, F. (2002). O brinquedo e a assistência de enfermagem à criança. Enfermagem Atual, 2(24), 6-17.

Ribeiro, C., Borba, R., \& Rezende, M. (2009). O brinquedo na assistência à saúde da criança. In E. Fujimori \& C. Ohara (Orgs.), Enfermagem e a saúde da criança na atenção básica (pp. 287-327). São Paulo: Manole.

Rocha, P., Prado, M., \& Kusahara, D.M. (2005). O brinquedo terapêutico como um modo de cuidar de crianças vítimas de violência. Ciência, Cuidado e Saúde, 4(2), 171-176.

Santos, L., Borba, R., \& Sabatés, A. (2000). A importância do preparo da criança préescolar para a injeção intramuscular com o uso do brinquedo. Acta Paulista de Enfermagem, 13(2), 52-58.

Silva, R., \& Sá-Chaves, I. (2008). Formação reflexiva: Representações dos professores acerca do uso de portfólio reflexivo na formação de médicos e enfermeiros. Interface - Comunicação, Saúde, Educação, 12(27), 721-734. 
256 Júnia Aparecida Laia da Mata Fujita et al.

Sobral, F., \& Campos, C. (2012). Utilização de metodologia ativa no ensino e assistência de enfermagem na produção nacional: Revisão integrativa. Revista da Escola de Enfermagem da USP, 46(1), 208-218.

Steele, S. (1981). Child health and family: Concept of communication. New York: Masson.

Vessey, J., \& Mahon, M. (1990). Therapeutic play and the hospitalized children. Journal of Pediatric Nursing, 5(5), 1563-1568. 


\title{
PROBLEMATIZATION METHODOLOGY WITH MAGUEREZ'S ARCH ON THERAPEUTIC PLAY TEACHING
}

\begin{abstract}
This study aimed to report the experience of teaching therapeutic play according to the Problematization methodology with Maguerez's Arch to nursing undergraduation students, as well as the obtained results. This teaching strategy was used with 52 students of a private institution in Curitiba, Parana State, Brazil. The five steps of Maguerez's Arch were implemented: 1. Reality observation; 2. Key-points; 3. Theorizing; 4. Solution hypotheses; 5. Application to reality - Practice. Students developed ten therapeutic toys. There was an opportunity of experiencing different aspects of the teachinglearning process, what denotes that undergraduation courses based on active methodologies and no longer limited to lectures on theoretical content have the potential of educating professionals well prepared to meet current health demands.
\end{abstract}

Keywords

Nursing education; Teaching; Problem-based learning; Play and toys

\section{APRENDIZAJE BASADO EN PROBLEMAS CON EL ARCO DE MAGUEREZ EN LA ENSEÑANZA SOBRE EL JUGUETE TERAPÉUTICO}

\section{Resumen}

Este estudio tuvo como objetivo reportar la experiencia de usar el aprendizaje basado en problemas con apoyo del Arco de Maguerez en la enseñanza del juego terapéutico en enfermería, así como los resultados obtenidos. La experiencia se llevó a cabo con 52 estudiantes de una institución de educación superior privada, en Curitiba, Paraná, Brasil. Fueron realizados los cinco pasos del Arco de Maguerez: 1. Observación de la realidad; 2. Puntos- 
258 Júnia Aparecida Laia da Mata Fujita et al.

clave; 3. Teorización; 4. Hipótesis de solución; 5. Aplicación a la realidad Práctica. El resultado fue la creación de diez juguetes terapéuticos. Fueron experimentados diferentes aspectos relacionados con el proceso de enseñanza-aprendizaje, y se señaló que una educación superior basada en el uso de metodologías activas y ya sin limitarse a la transmisión de contenido teórico tiene el potencial de formar profesionales más preparados para satisfacer actuales demandas de salud.

\section{Palabras-clave}

Educación en enfermería; Enseñanza; Aprendizaje basado en problemas; Juego e juguetes

Recebido em agosto/2015 Aceite para publicação em março/2016

i Programa de Pós-Graduação em Enfermagem, Faculdade de Enfermagem, Universidade Estadual de Campinas, Brasil.

ii Faculdade de Enfermagem, Universidade Estadual de Campinas, Brasil.

iii Faculdade de Enfermagem, Universidade Estadual de Campinas, Brasil.

iv Instituto de Corresponsabilidade pela Educação \& Universidade Livre para a Eficiência Humana, Brasil.

Toda a correspondência relativa a este artigo deve ser enviada para: Júnia Aparecida Laia da Mata Fujita, Avenida Presidente Affonso Camargo, $n^{\circ} 2125$, apartamento 141, Cristo Rei, CEP: 80.050370, Curitiba, Paraná, Brasil. E-mail: jumata.2905@gmail.com 